\title{
Education Towards Differences: Preventing Gender and Sex Discriminations in Subjects in the Age of Development
}

\author{
Mariano Gianola \\ Sociologist, SINAPSI, University of Naples "Federico II" \\ Giuseppe Masullo \\ Assistant professor in Sociology and social research \\ University of Salerno, Department of Humanities, Philosophy and Education \\ (Dipartimento di Scienze Umane, Filosofiche e della Formazione - DISUFF)
}

\begin{abstract}
The present contribution addresses the issue of preventing and combating gender and sex discrimination in subjects in the age of development and, specifically, children. In our society, characterized by an ideological sexist, genderist and heterocentric matrix, identities that cannot placed within the socially constructed and accepted stereotypes of normality are - often - victims of abuses and they are denied equal treatment. In order to raise awareness of the need to respect personal and social differences, more and more initiatives are being created aimed at promoting a non-discriminatory attitude towards gay, lesbian, bisexual, transgender, nonconforming and queer people. Among such initiatives, the construction and narration of stories for children explaining the concepts inherent in the culture of differences, are a valid tool for fostering a climate and a cultural structure free of gender and sex stigmatization and instead aiming at enhancing "difference", considering it a positive possibility just like socially-accepted states. The essay, after a brief description of the characteristics of language, attitudes and relationship with reality in subjects in the age of development, examines the methodological and ethical approach to be used with children, so as to allow them to understand the possibility of different forms of identity and otherness. Preventing and countering prejudices arising from beliefs and social models that help in reproducing every day, in civil society, discriminations, harassment, and unequal treatment against many people, represents a mission to create and reproduce an inclusive and democratic society.
\end{abstract}

Keywords: gender / sex discrimination, minors, narration, fairytales, prevention.

\section{Introduction}

Families, schools, and the media are the social and/or institutional actors involved in the socialization process, i.e., the cognitive, social, relational, and inter-ethnic process through which the child begins to structurally internalize beliefs, rules, values, as well as the codes of perception and representations of social reality.

Such institutions should thus be the agents capable of responding to the societal structures' needs for change, in their mission to promote the learning of shared cultural models. Their ultimate aim is to interpret, understand, and support the ongoing historical, cultural, political, economic, and anthropological changes affecting societies (Dubar, 2004).

Societies are aggregates that must be understood in their processuality. For this reason, they should not be considered as static and rigid sets, but rather as synergic elements endlessly addressing the challenges of change as an intrinsic element for their survival (Luhmann, 2014).

In a perspective encompassing and supporting changes, the various forms of personal, social, and cultural identity must be considered and recognized as fluid, transversal, and multidimensional entities. Their definition, recognition, and affirmation are a fertile ground for the construction of a society that is inclusive, equal, and free from those prejudicial structures often used to interpret and represent forms of normalities perceived as distant and/or different from the socially approved ones (Mangone, Masullo, 2015). 
To bolster a culture that posits relativism, appreciation of differences, and ideological non-discriminatory ideals as well as supporting equal opportunities, it is thus essential to promote - in civil society as in every other social context - initiatives designed to prevent and counteract abuse. The latter comes in many forms and is aimed at those differences which, even today, are subject to social stigma due to the cultural processes allowing for the association of negative labels to models not conforming to the collectively approved ones (Masullo, 2015).

The need to promote actions aimed at boosting social inclusion is a challenge and an ethical duty that must embrace the various institutional actors engaged in education.

The development and implementation of processes, strategies, actions, and relationships that favour this inclusion should be pursued in various and diverse ways depending on a number of variables. Among these, we find the cultural specificities of the various contexts, the social factors there existing, and the target they are destined for.

Instilling respect for differences is an essential goal, especially for subjects whose personality is under formation - namely, subjects in the age of development. Given their characteristically flexible and adaptable language, children can easily learn the ideological, symbolic, and value devices designed to support equal opportunities. This enables them to perceive differences as an intrinsic resource and, furthermore, to mature a positive attitude toward situations differing from sociallyaccepted normality (Mari, 2013, Roverselli, 2015).

The present contribution ${ }^{1}$ describes some tools destined to children for preventing and combating discrimination ${ }^{2}$. More in detail, we will address those narrative tools (or fairy-tales) aimed at combating the abuses, harassments, and violence related to gender identities and sexual orientations that still represent the source of social exclusion and non-equal treatment towards gay, lesbian, bisexual, nonconforming, transsexual and transgender people 3 .

Before proceeding with the description, we will provide a brief overview of the characteristics of children's language, to better understand the features and aims of the initiatives implemented.

\section{The language of subjects in the age of development ${ }^{4}$ and its peculiarities}

Children's minds and attitude towards life is characterized by multiplicity, fluidity, ductility, and non-conventionality. Indeed, children, in their experience and psycho-cognitive development, are yet to internalize the socially endorsed stereotypes, patterns, and models at play in their environment (cultural references) (Nesdale, 2002).

The features listed above, along with their curiosity and sense of discovery, allow children to accept and understand social changes - unlike adults - in an open and flexible way, quite detached from prejudice (Aboud, Doyle, 1996, Troyna, Hatcher R. 1993).

Mental versatility, coupled with a lack in the rigid internalization of culturally-shared social conventions and models, allow children to perceive differences as a resource. In addition, it can promote an attitude free from prejudices against what they perceive or represent as unlike themselves.

In this perspective, considering fluidity and transversality, the initiatives and interventions aimed at preventing and combating discrimination - if they are conceived and implemented based on the characteristics of the child's very world can advance the interiorization of positive values, beliefs, and representations concerning otherness (Masullo, 2016).

To encourage this process, it is essential to avoid creating taboos on the issues to be addressed. Very often, the projection of adults' prejudices on certain arguments can be a strong device for creating and/or reinforcing the child's "reserve" against certain social realities or forms of normality (Nesdale, 2002).

\footnotetext{
1 This contribution results from a joint effort by the authors. More specifically and for authorship reasons, the introduction and sections 4 , 4.1, 4.2. and 4.3 were written by Mariano Gianoloa, while sections 1 and 3 were written by Giuseppe Masullo. The authors co-wrote section 2 and the conclusions.

2 Proposed as an educational tool for families and schools.

3 And also towards those people who refuse to comply with rigid gender and sexual stereotypes, feeling that these static definitions and/or categorizations are ill-suited to their multidimensional identity, way of being and self-identification.

4 The term subjects in the age of development refers to children and adolescents. Among them, we will refer only to children, as the narrative tools examined in the present paper are thought and realized for them, peculiarities of their language and their experiences.
} 
It may therefore happen that in some contexts, such as family or school, without conscious intent, some issues - such as love between people of the same sex, gender differences, homosexual parenting or non-conformities to rigid gender models - are not subjects of conversation ${ }^{1}$ with the children because it is assumed that they would not understand or, wrongly, would even be negatively affected. In particular, issues related to gender identities and sexual orientation still represent a source of taboo and a generalized remnant of that untouchability that conceals a profoundly prejudicial attitude (Masullo, lovine, 2016).

According to current researches, there is no direct link between addressing gender and sexual orientation issues and influences on children's personal identity. Moreover, sexuality and gender identity in children are still "under construction" and, therefore, also linked to their future life experience. These two core points considered, some very important aspects (ibidem) have to be specified. First, that homosexuality is not a pathology (Rinaldi, 2012) and that homosexual parents (just like heterosexual ones) are able to raise well-balance children and promote their healthy psycho-physical development (Parisi, 2017, Bastianoni, Baiamonte, 2015). Second, that, with respect to transgenderisms and/or gender non-conformities, science is depatologizing the gender disorder status (Drescher, 2014).

As a result, initiatives aimed at preventing discrimination can be a useful tool to form and support tomorrow's citizens so that they are better aware of the fact that differences are an inherent and paramount aspect of humanity, to prevent stigmatization and prejudicial attitudes towards the other.

\section{The methodological-conceptual approach adopted and its ethical implications}

Thinking, writing, and designing children fairy-tales is no simple task. First of all, because of the need to find that "common world", that conceptual, symbolic and thought-related space that will create a synergy between the perceptive world of the child and that of the adult (Aldi, 2014).

Different languages, categories, meanings, perceptions, and interpretations must find the right coordinates so that what is transmitted by the adult is concretely understandable and usable by the child.

To that end, it is necessary to define a structure of meanings that can be easily codified and acquired by the child, thus favouring the translation of the concepts transmitted by the adult into positive messages for subjects like children, who are growing and confronting/discovering social reality (ibidem).

To the difficulties inherent in this process, one should add the fact that certain topics addressed in the fairy-tales can often be perceived as leagues apart from (if not altogether alien to) the reality experienced by the child. All this should prompt the professionals of the interventions aimed at preventing and contrasting discriminations to accurately create (and question) tools targeted at delivering positive messages (Bernardi, 2009).

The first step, in order to create the synergy described above, is to use a language with easy-to-understand communicative codes for children. This understanding is not related merely to formal aspects (e.g., linguistic ones, such as the use of words, expressions, and phrases typically used by children) but also to the nature of the children's perceptive filter and the way they relate with and/or interpret reality (Ferrario 2000). For example, addressing the issue of non-discrimination with regard to gender stereotypes, entails first explaining to the child what society thinks and considers as typically male or female. This crucial step should preferably be taken before deconstructing the rigidly stereotypical conceptions favouring and reproducing discrimination against those who do not conform to the social rules determining how men and women should identify themselves, act, and talk. Obviously, this discourse must be calibrated according to a series of variables depending on conditions such as age, cultural environment, space-time, and/or other aspects of the child's experience. For these reasons, it is not possible to provide an all-valid rule for any circumstances. The way to address specific issues in fairy-tales always depends on specific conditions and situations.

The translation of concepts belonging to the adult world into meanings that can be understood by the child should also be made considering the latter's priorities, needs, and supposed interpretations. Indeed, adults too often convey their prejudice to children by unconsciously projecting it onto the addressed issues, despite the lack of specific prejudice on the subject by the children themselves (Aboud, Doyle, 1996). For example, parents intending to explain that other forms of normality are as legitimate as traditional ones (e.g., same-sex families) may incorrectly say that there are "normal families" (such as

1 Or they are treated improperly (for example, with discriminatory nuances). 
those formed by a mother and a father) and "other families" (such as those formed by two mothers or two fathers). The error lies in associating the concept of normality to traditional families alone, which in itself implies a discriminatory attitude towards non-traditional families. For this reason, during the explanation, the characteristic of normality should be attributed to all types of family, while emphasizing their inherent difference. Additionally, it should be stressed that, although families can be different, they all provide a healthy environment for the child. It would be a positive and constructive step to reemphasize the equality of the concept of family, regardless of actual differences. The language of children, being different from that of adults, may lead them to focus their attention on differences other than those stressed by the adult. For example, a child may consider "strange" an adult's fear of the dark, rather than her feeling to belong to a different gender than the one she was attributed at birth¹.

As pointed out above, in a perspective aimed at promoting an inclusive society it is unadvisable to create taboos. Children are active subjects that need to be prepared and accompanied in discovering society, the world and, in general, the social reality with its various shades and changes. Many issues believed by adults not to be understandable by children can instead be addressed and proposed to their reflection (ibidem). Death, fear, suffering, organ donation, war, parental separation, homosexuality, transgenderism, sexuality, gender differences, social, religious and ethnic conditions, disability, are all issues that should be addressed in order to allow their understanding - even if, for someone in the age of development, they are not "nice" subjects. Creating a hyper-protective cocoon around children can conversely cause traumas whenever they discover unknown realities to which they cannot attribute a personal sense.

How complex, unknown or distant subjects are addressed is of paramount importance. The ways of creating a structure of meanings and the language used are what lead to traumatic situations for the child, rather than the arguments themselves (though painful or not belonging to his/her daily experience). In this sense, as noted above, it is important not only to use appropriate terms and words, but also to adopt a communicative substance that accompanies the child in his/her understanding those complex, difficult or sad issues (Ferrario 2000). For example, adults explaining the issue of death to children should not merely use words such as "going to heaven", "falling asleep", "traveling to another world", but rather explain that all life-forms (animals, plants, people) as well as unanimated objects (planets, satellites, stars, etc.) experience a natural end.

Using a method that prepares children for learning certain topics can decrease the negative impact, discomforts, and frustrations that they may experience in discovering these realities without a prior explanation from an adult.

Very often, taboos and prejudices are unknowingly reproduced by adults in their explanation to the child. This situation may also arise among experts and professional figures working in the field of non-discrimination: no one is flawless. The important thing, in this case, is to create a generic narrative structure that is open and that places the individual, collective, cultural, or any other form of difference, as legitimate and inherent possibilities of identity.

The aforementioned requirements may, together with school and familial interventions, favour a value structure that allows the child to perceive the different forms of normality within a synoptic framework including various alternatives where no one is to be considered better than the other. This, in turn, with the purpose of favouring an attitude as free as possible from prejudice and/or excessive stereotypical prescriptions aimed at:

Considering differences as an opportunity and valuing them;

Preventing stigma, violence and abuse;

Considering societies and, in general, the world as arrangements whose peculiarity is represented by the differences in the various forms of identity and existence, each with its own dimensions and nuances;

Creating and promoting people-oriented awareness-raising opportunities;

Not considering relativism and differences according to scale of importance and hierarchies affecting people, cultures, languages.

\section{Narration as an anti-discrimination tool}

\footnotetext{
${ }^{1}$ As for transgender people.
} 
Among the instruments for preventing and contrasting discrimination, narrative is not to be underestimated in the didactic, educational and experiential fields (Bocci, 2013).

Narration is the conceptual and symbolic device through which the transmission and learning of information and positive values can take place. This thanks to the following peculiarities offered by this device:

Empathy: advances the understanding of other realities and the promotion of cognitive behaviours contrasting the prejudices caused by a perceived distance from certain persons, phenomena or social objects;

Metaphor: allows to translate complex concepts, far distant from personal experience, in easily understandable and codifiable images and meanings;

Fantasy: allows the above-mentioned translation through the creation of "appetibile" arrangements, facilitating the learning processes of certain concepts in order to structure perceptions, visions, attitudes, and meanings in a particular direction (in our case, in the direction of an inclusive culture) (Compagnaro, Dallari, 2013).

Narration thus becomes an educational tool designed to modify or counteract prejudices, ideological behaviors, discriminatory attitudes, and the general perception of human and social differences as something negative.

"Narrating" does not mean just providing information; the narration process is complex and articulated. There are a number of considerations to make in order to ensure that the text (not only in its lexical elements but also in its symbolic images) is understandable, codifiable, interpretable by the user.

One of the key elements for an effective narrative is adapting its language to that of the recipients (Dallari, 2013). The contents of the communication, even if they dist from the intended recipients' personal experience, are to be accessible, comprehensible, and codifiable. This facilitates several processes related to the learning and transmission of information aimed at interiorizing positive messages, promoting new awareness, prompting the formation of non-discriminatory attitudes, and/or structuring non-prejudicial perceptions towards specific social realities.

The terminology used is often less important than the creation of a structure of meaning expressing, in a clear, linear, and consistent way, the values that are to be communicated, transmitted, and disseminated.

While repetitions should be avoided, "intensifiers" should not be underestimated. It is possible to resume a certain concept several times to allow for its internalization. Intensifiers should not necessarily be the same as the original stimulus, and they sometimes can be structured differently. For example, a concept expressed in words can then be resumed and repeated through evocative images or ones that are presumed to be meaningful for the recipient.

For subjects in the age of development, narration is more complex in its structuring and implementation. For this reason, some crucial variables are to be accurately considered and weighted: the children's language, their discovery of social reality, the distance of their everyday experience from certain themes, as well as personal, social, and cultural factors (Ruiz, Campos, Hoster, 2013).

Following the above reflections, the following section will describe some fairy-tales intended for children aimed at preventing, counteracting and combating discriminations related to gender identities and sexual orientation. We will give particular attention to three elements:

The general objectives of the initiatives;

The conceptual translations, understood as those lexical instruments, in the form of metaphorical and non-metaphorical constructs, structuring the narration in order to transmit and/or reinforce anti-discrimination values promoting an inclusive culture;

The charcters and illustrations used, i.e., the images, symbolic elements, and illustrative frameworks aimed at reinforcing or communicating specific concepts. The characters can take various forms: real (people, animals, nature, planets, etc) or fantastic (goblins, being from other dimensions or hybridization between real and fantastic figures).

\section{Children's fairy-tales to prevent gender and sexual stigma}


The purpose of the following section is to describe some of the initiatives aimed at preventing and combating abuse and stigma against gender and sexual orientation.

Gay, lesbian, bisexual, transgender, transsexual, gendernonconforming, and queer people are victims of discrimination caused by a series of stereotyped and socially shared beliefs that create, favour, and/or increase prejudices, negative attitudes, and fears about differences. The latter are perceived as deviation from the social parameters delineating normality.

In order to prevent the continuation and reproduction of such discriminations, some initiatives focused on narrative tools aimed at children, who will be the actors accountable for the construction of future societal equilibria.

The main purpose is to counteract those ideological ideals entailing excessive prescriptivity of gender stereotypes related to gender and sexual orientation. In such schemes, homonegativity and transnegativity hinder the achievement of equal opportunities for many people.

Destroying stereotypes and discriminating concepts, starting with fairy-tales, means enhancing the mental plasticity of children, supplying them with concepts stemming from positive values.

In the following sections, we will describe the narrative tools motivated by the aforementioned goals. We point out that that the fairy-tales here mentioned are e-books that can be downloaded free of charge to allow for their wide distribution.

\section{Gender nonconformity, "T" identity and same-sex families}

Avoid addressing certain issues with children can often be a mistake. Furthermore, this may cause them fewer opportunities for being acquainted - and compare themselves - with reality in its full complexity, supporting their conscious selfdetermination. There is therefore no reason not to deal with the issues of transgenderism and gender nonconformities. Reticence is often linked to two types of prejudice by adults. The first concerns their attitude to identities that do not conform to socially shared gender models; the second refers to their belief that children could not possibly understand the issues addressed. But all things are new to children: they are just discovering wars, science, sports and pollution. Explaining to them what it means to be a transgender person is a legitimate educational task.

The fairy-tale Trans Cuore. L'amore attraversa i confini (Trans Heart. Love Crosses Boundaries) (Gianola, 2016a) is born with the first and foremost objective of explaining to children what it means to identify oneself with a different gender than the one assigned at birth on the basis of biological sex. The knowledge of this reality also helps in preventing, counteracting, and combating discriminations against " $T$ " persons.

Being aware of how a transgender person can experience discrimination, emotional, social, and relational discomfort, as well as frustration, is one of the conceptual devices promoting an empathic approach, an inclusive attitude, and a positive perception of differences.

Due to its educational purposes, the e-book is highly descriptive. It does not recount complex adventures, rather aiming at transmitting some key concepts and reflections on "T" people.

To achieve these goals, two key characters of the story are introduced - Heart and Brain - to allow the child to understand the identity condition experienced by transgender people: the psychological feeling to belong to a gender differing from the one prescriptively assigned at birth, to go beyond the definitions imposed by society and to cross rigid ideological barriers.

In addition, the tale draws also attention to the family and to the concepts of adoption, monoparental families, and samesex families. Such reflections are addressed with an inclusive perspective, with the aim of supporting and promoting equal opportunities.

The text also includes the Little Manual Against Discrimination, that resumes in scientific terms some concepts explained in the fairy-tale. It explains the concepts of stereotype, prejudice, violence, and discrimination, and it also helps children in supporting themselves and/or their schoolmates and peers whenever they become victims of bullying.

Table 2. Explaining transgenderism and discrimination against " $T$ " people 
Preventing and combating discrimination against " $T$ " people

Explaining to the child what it means to be a transgender person

Allowing the child to understand the stress, discomfort, and frustration caused and by gender stigma

Enhancing the child's awareness of - and respect for - differences and otherness

Promoting respect for monoparental families and/or for families with a transgender parent

Explaining the concepts of discrimination, stereotype, prejudice, and violence

Explaining how to behave when a schoolmate or frient becomes a victim of bullying
Explaining to the child that there are no grounds for discriminating against people who do not want to comply with gender stereotypes

Using the word "trans" without any kind of taboo to allow the understanding of its meaning and, moreover, the existence of people who identify themselves

by that word

Fostering an understanding of the distress emotional dynamics characterizing the lives of discriminated people

Transmitting, through the narrative structure, the importance and beauty of equality and of the various forms of difference

Highlighting how, regardless of its form, the family is the symbolic core embracing its members with respect and love

Describing the meaning of these terms, often through examples that directly refer to situations understandable for the child

Coaching the child on the behaviour to adopt when a friend or schoolmate is offended or treated unequally by others. Helping the child becoming a "voice" to explain to his peers the meaning of social inclusion
Fantasy characters (such as Heart and Brain) living in the body of the tale's protagonist

Fantasy characters and stereotypical objects

Fantasy characters

Symbolic characters: butterflies with names relating to positive social values and concepts belonging to the textual structure

Characters and concepts belonging to the textual structure

Characters and concepts belonging to the textual structure

Concepts belonging to the tale's structure

\section{Love, homosexuality and homonegative ideologies}

It is important to talk to - and with - children about the feelings and relationships that unite people, either in general (friendship) or in a more specific sense (love).

The most popular and well-known fairy-tales talk of love between a man (male) and a woman (female). Often, they depict the man assuming and performing a protective function against the woman, who is weaker party.

In a perspective aiming at equality, it is necessary to explain to children that love is a universal feeling, hence independent from social constraints and models. For example, a princess might fall in love with her gardener instead of a prince, or she might love another woman.

Sole ama Sole (Sun loves Sun) (Gianola, 2016b) aims at achieving these goals: explaining to the child that people are (or should be) free to love whomever they want, beyond the social structures and conventions undermining personal freedom.

The tale aims at preventing and countering discrimination against homosexuals and their feelings. It therefore addresses love between same-sex people as natural and normal and, above all, it conveys what science says on the issue - namely that homosexuality is not a disease.

The approach used in this text is the metaphorical translation; in order to better convey the above-mentioned meanings and make them understandable for children, the author used natural phenomena, planets, stars, and water. 
Using these characters allows the author to broaden the horizons on the concepts conveyed by promoting the idea of the universality of feelings, which are independent of social status and other socially desired conditions.

In addition, the story highlights two elements that reflect many current societies and that should be addressed with children - according to their language - to support their acquaintance with the surrounding reality. The first concerns the existence, in many social settings, of a discriminatory ideological climate towards homosexual people, which often leads many of them to experience frustrations and discomforts from an emotional and relational point of view. The second emphasizes that the dynamics of life do not always end happily and, unfortunately, sometimes certain goals cannot be achieved. This latter aspect is highlighted when Yellow Sun's father fails to understand his son's love for Red Sun (protagonist and coprotagonist, respectively) and banish him from the kingdom.

Table 3. Normality and naturalness of same-sex love relationships

AIMS

Enhancing awareness of the universality of feelings as a dimension free from social rules

Preventing and combating discriminatory attitudes towards homosexuality and prejudice against homosexual persons

Promoting the idea of social support and mobilization aimed at combating inequality

Rispetto dei sentimenti propri e di quelli altrui Respect for their own feelings and those of others

Explaining the existence of discrimination situations and making the and make the child aware of them

Explaining that, despite dialogue and mediation, the dynamics of life do not always follow the desired path

\section{CONCEPTUAL TRANSLATIONS}

Explaining to the child that it is not a mistake to have feelings for someone, no matter who he/she is

Encouraging the child to understand that homosexuality is natural and it is not a disease. Highlighting the normality of affective and sexual orientations towards a person of the same sex

Teaching the values of solidarity and cooperation in favour of some missions.

The support, mobilization, and assistance of others in order to promote an inclusive society is a key resource for promoting equal opportunities

Encouraging the child to understand how important it is to freely choose who to love, beyond the social impositions that may result from it and/or their desirability and expectations existing in a particular culture

Encouraging the understanding of the existence of some social rules and cultural beliefs, often automatically applied, that discriminate against certain forms of love and/or identity that do not fall within the socially approved frameworsk

Teaching that the goal of solidarity and the promotion of a culture that values differences are not sustained by everyone. Highlighting the existence of individuals that remain attached to discriminatory attitudes that they constantly reproduce.

\section{FIGURES EMPLOYED}

Fantasy characters: Natural Phenomena (e.g., Universe, Suns and Moons)

Fantasy characters: Natural Phenomena (e.g., Universe, Suns and Moons)

Fantasy characters: Natural Phenomena (e.g., Universe, Suns and Moons). In particular, the characters of Rainbow and Moon of Hope.

Fantasy characters: Natural Phenomena

\section{(e.g., Universe, Suns and Moons)}

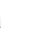


A culture that aims to promote social inclusion should not be based on rigid impositions and/or constraints on the expression of personal identity. It should represent an ideological position respecting those who conform to socially shared stereotypes as well as those who, totally or partially, do not, recognizing and protecting them both. It should promote freedom of expressions, identities, and self-presentations; it should favour and include the various forms of normality in order to recognize and defend them and to guarantee equal treatment and representation. This perspective, with respect to the issue of gender, object of the following discussion, wants to prevent discrimination against those whose gender expression does not rigidly conform to stereotypes and models defining the drastic male/female binary pattern.

The aim of Pioschino e i folletti un po' maschio e un po' femmina (Pioschino and the Pixies a bit male and a bit female) (Gianola, 2016c) is to promote a pro-differences culture that supports the free expression of one's self-presentation, lifestyle, and/or identity without adhering to stereotypical homologation dictated by binary patterns that highlight the existence of gender manifestations as extreme and opposite (extreme masculinity or femininity).

Duccio, a child from a world that envisages only a full homologation to rigid stereotypes of masculine and feminine, meets Pioschino, a pixie of the transversality of gender expressions. It is a metaphor for promoting a culture of differences free from prejudice towards those who do not intend to conform to models perceived as rigidly prescriptive.

The basic assumption guiding the narrative structure is to assert and recognize first and foremost the existence of variety and transversality, as well as of identities differing from the conventionally intended ones, and to promote awareness of the existing balance between Nature and human beings.

In Pioschino's world, unlike in Duccio's, there is no clear male/female distinction, so that the inhabitants do not even know these terms. This idea does not aim at denying the dichotomy, but rather at opposing its rigid application and normativization, to favour respect and recognition for those people who do not intend to conform to binary gender choices. The objective is to assert the existence and the admissibility of the various possible forms of self-expression, both stereotypical and non-stereotypical, provided that the right to freely manifest and express one's identity is respected in order to promote self-determination. Further objective is to oppose the idea of the anthropocentric primacy of existence by promoting perspectives and life-style approaches in balance with nature and identity variety.

Table 4. Gender nonconformity, gender variances, free self-expression and self-manifestation

\begin{tabular}{|l|l|l|}
\hline AIMS & CONCEPTUAL TRANSLATIONS & FIGURES EMPLOYED \\
\hline $\begin{array}{l}\text { Supporting free self- } \\
\text { expression and play }\end{array}$ & $\begin{array}{l}\text { Considering play and self-expression through nuances that } \\
\text { see male and female not as a problem, but as an identity } \\
\text { aspect to be considered equally and with the same dignity as } \\
\text { others }\end{array}$ & $\begin{array}{l}\text { Fantasy elements: Pixies of the } \\
\text { transversality of gender expressions }\end{array}$ \\
\hline $\begin{array}{l}\text { Preventing and } \\
\text { combating } \\
\text { discrimination against } \\
\text { the transversality of } \\
\text { gender roles and/or } \\
\text { gender non-compliance }\end{array}$ & $\begin{array}{l}\text { Encouraging the understanding that gender non-conformities } \\
\text { are not negative, being just one of the various forms of } \\
\text { identity that human beings can assume. Considering variety } \\
\text { of self-expression as an asset and not as a limit. Raising } \\
\text { awareness of the importance of equal opportunities and } \\
\text { equality, respecting differences }\end{array}$ & $\begin{array}{l}\text { Fantasy elements: Pixies of the } \\
\text { transversality of gender expressions }\end{array}$ \\
\hline $\begin{array}{l}\text { Promoting the } \\
\text { understanding of other } \\
\text { ways of living and } \\
\text { conceiving human } \\
\text { existence }\end{array}$ & $\begin{array}{l}\text { Encouraging the understanding of other possible forms of } \\
\text { identity and, in general, of otherness. Highlighting the } \\
\text { existence of other worlds, logics, and social dynamics }\end{array}$ & $\begin{array}{l}\text { Fantasy elements: Pixies of the } \\
\text { transversality of gender expressions } \\
\text { and other worlds characterized by other } \\
\text { operational arrangements. }\end{array}$ \\
\cline { 2 - 3 } & $\begin{array}{l}\text { Human Characters: Duccio, a child from } \\
\text { planet Earth }\end{array}$ \\
\hline $\begin{array}{l}\text { Raising awareness of } \\
\text { the human-nature } \\
\text { connection }\end{array}$ & $\begin{array}{l}\text { Enhancing and promoting the awareness of human existence } \\
\text { in interconnection with nature. Synergy between the various } \\
\text { existing forms. }\end{array}$ & $\begin{array}{l}\text { Fantasy elements: Pixies of the } \\
\text { transversality of gender expressions } \\
\text { and worlds where nature is an integral } \\
\text { part of the relationship between life } \\
\text { forms }\end{array}$ \\
\hline
\end{tabular}


Raising awareness of the synergy and inclusion of the various forms of identity, despite their differences
Highlighting the connection and synergy between the diverse possible identities and the interrelation between different worlds and realities
Fantasy elements: Pixies of the transversality of gender expressions and worlds where nature is an integral part of the relationship between life forms Human Characters: Duccio, a child from planet Earth

\section{Some examples of meanings transmitted through the images}

In order to provide a more complete overview of the fairy-tales analysed in the present contribution, we will draw attention to some of the illustrations in the texts described above, showing how they can strengthen the content of the text or, sometimes, even autonomously express meanings understandable by the child without the support of words.

The author's decision of personally drawing these images is motivated by his choice of favouring consistency between the texts and the values which he wanted to emphasize. In addition, he wished to focus the readers' attention on certain symbolic elements through simple, linear images, easily understandable and codifiable by the child.

Metaphors have been used mainly in the textual part, leaving the images easy to codify, so that the child can learn and/or reinforce the content and topics discussed.

Figure 1. Cover of Sole ama Sole (Sun Loves Sun), depicting Rainbow accompanying Yellow Sun to his partner Red Sun. Gianola, M. (2016), Sole ama Sole, "Gender Identity Culture" Foundation, Naples.

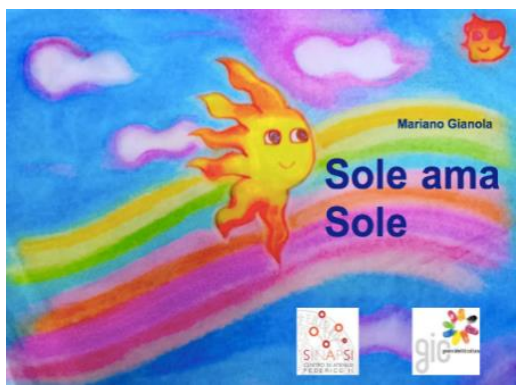

Figure 2. Yellow Sun is imprisoned to prevent him from seeing his partner Red Sun. He then escapes thanks to Rainbow's help. Gianola, M. (2016), Sole ama Sole, "Gender Identity Culture" Foundation, Naples.

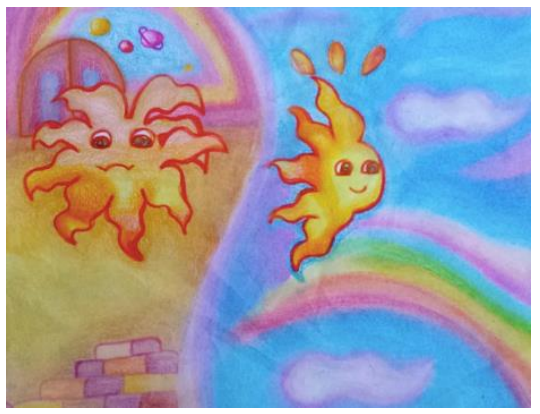

Figure 3. Yellow Sun finds he is falling in love with Red Sun. Gianola, M. (2016), Sole ama Sole, "Gender Identity Culture" Foundation, Naples. 


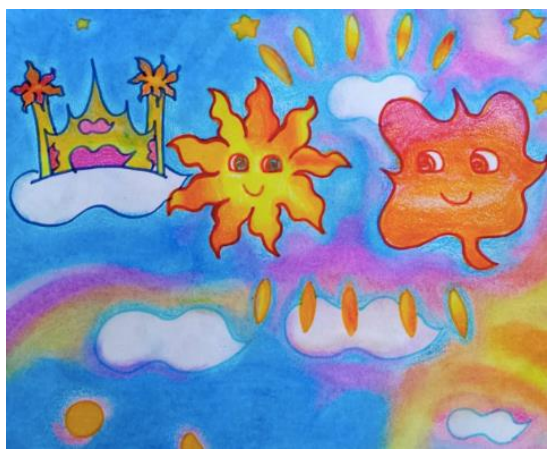

Figure 4. Cover of Pioschino e i Folletti un po' maschi e un po' femmine, where Duccio, a child from Earth, discovers the existence of different realities where the equilibrium between nature and the various forms of existence is paramount. Gianola, M. (2016), Pioschino e i Folletti un po' maschi e un po' femmine, "Gender Identity Culture" Foundation, Naples.

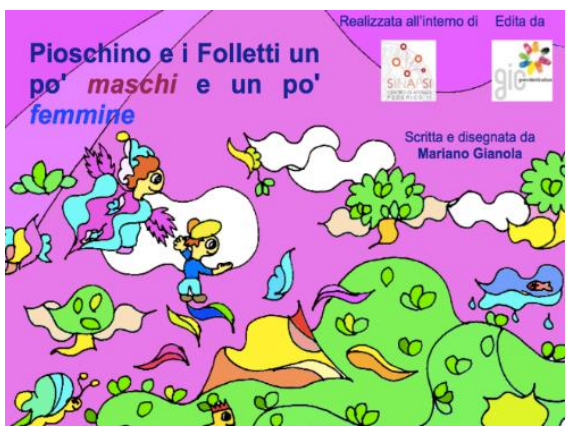

Figure 5. A pixie whose identity expressions go beyond gender dichotomies and whose identity, in his world, is not subject to social stigma. In his identity, this pixie includes different nuances and/or dimensions belonging to both the stereotypes defining male and female, considering it as an added value. Gianola, M. (2016), Pioschino e i Folletti un po' maschi e un po' femmine, "Gender Identity Culture" Foundation, Naples.

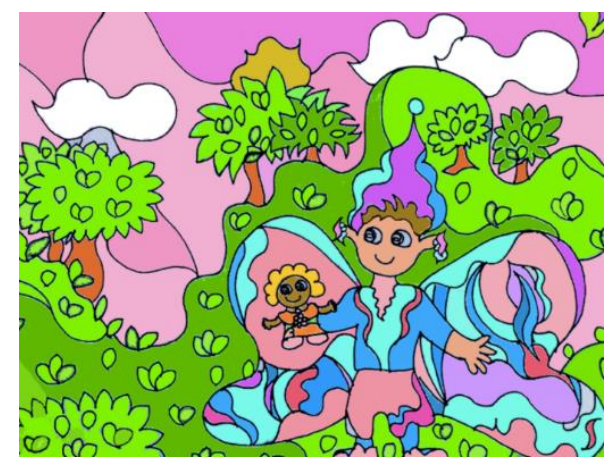

\section{Conclusions}

As discussed above, fairy-tales can be an effective instrument in favouring a non-discriminatory attitude and a positive perception of other people's differences, without prejudices and unfounded stereotypied opinions.

Being mere tools, it often happens that they are not enough in themselves to implement actions able to fully modify beliefs, opinions, and/or actions based on misconceptions about the forms of socially stigmatized difference. 
Nevertheless, fairy-tales as a conceptual, narrative, and symbolic tool can be a crucial stimulus to counter discriminatory attitudes, particularly if supported by parallel actions, relationships, or processes in which certain issues can be addressed with an inclusive approach.

Reading a fairy tale with a parent, making it part of a lesson, discussing certain issues within families, are but few of those processes supporting, together with narrative tools, those actions and behaviours aimed at promoting a culture that champions differences and equal opportunities.

Social models cannot be changed suddenly, and yet they can progressively evolve through a series of paths of various nature aimed at promoting equality and solidarity. For this reason, what may appear to some as small actions in can actually implicitly be agents of change, especially one for the better.

\section{References}

[1] Aboud F. E., Doyle A. B. (1996), Parental and peer influences on children's racial attitude in "International Journal of Intercultural Relations", Issues 3-4, 20, pp, 371- 383

[2] Aldi G., (2014), Educare con le fiabe: Come sviluppare l'intelligenza emotiva dei bambini (Educazione Olistica), Edizioni Enea, Milano

[3] Bastianoni P., Baiamonte C. (a cura di) (2015), Le famiglie omogenitoriali in Italia. Relazioni familiari e diritti dei figli, Edizioni Junior/Gruppo Spaggiari, Parma.

[4] Bernardi, M. (2009), Infanzia e metafore letterarie: orfanezza e diversità nella circolarità dell'immaginario, Bononia University Press, Bologna.

[5] Bocci F. (2013) (ed.) Altri sguardi. Modi diversi di narrare la diversità, Pensa Multimedia, Lecce

[6] Campagnaro, M., Dallari M.(2013) (eds.), Incanto e racconto nel labirinto delle figure.: Albi illustrati e relazione educativa. Edizioni Erickson, Trento

[7] Dallari M, (2013), Raccontare come pratica di cura. Dal concetto di intenzionalità a quello di cura, in Campagnaro, M., Dallari M.,(2013) (eds.), Incanto e racconto nel labirinto delle figure.: Albi illustrati e relazione educativa. Edizioni Erickson, Trento, pp. 15-58

[8] Drescher J. (2014). Controversies in Gender Diagnoses. In "LGBT Health" vol. 1, Number 1, pp 9-15

[9] Dubar C. (2004), La socializzazione. Come si costruisce l'identità sociale, I Mulino, Bologna

[10] Gianola, M. (2016a), Trans Cuore. L'amore attraversa i confini, Ateneapoli Editore, Naples. Initiative by the SInAPSi University Center - Services for the Active Inclusion and Participation of Students at the University of Naples Federico II and downloadable on the Ateneapoli website at: www.ateneapoli.it/bookstore/transcuore-lamore-attraversa-i-confini-ebook

[11] Gianola, M. (2016b), Sole ama Sole, "Gender Identity Culture" Foundation, Naples. Initiative by the SInAPSi University Center - Services for the Active Inclusion and Participation of Students at the University of Naples Federico II and downloadable on the Ateneapoli website at: www.sinapsi.unina.it/le favole di SInAPSi

[12] Gianola, M. (2016c), Pioschino e i Folletti un po' maschi e un po' femmine, "Gender Identity Culture" Foundation, Naples. Initiative by the SInAPSi University Center - Services for the Active Inclusion and Participation of Students at the University of Naples Federico II and downloadable on the Ateneapoli website at: www.sinapsi.unina.it/le_favole_di_SInAPSi

[13] Ferrario A., (2000) Fiabe e narrazioni, in G. Favaro (ed.), Alfabeti interculturali, Guerini, Milano.

[14] Luhmann N., (2014), Introduzione alla teoria della società, Pensa Multimedia, Lecce

[15] Mangone E., Masullo G., (2015) (eds.) L'Altro da sé. Ri-comporre le differenze, FrancoAngeli, Milano.

[16] Mari G., (2013), Educazione e alterità culturale, La Scuola, Brescia

[17] Masullo G., (2015) Tra Noi e l'Altro: Le rappresentazioni sociali dello straniero in Mangone E., Masullo G. (eds.), L'Altro da sé. Ri-comporre le differenze, FrancoAngeli, Milano, pp. 93-111.

[18] Masullo G., lovine F., (2016) The dynamics of eros: teenagers and socialization to sexuality in Italian atypical families, "European Journal of Multidiscipliary Studies", vol. 1(4), Jan-April, pp. 200-210

[19] Nesdale D. (2002). "Social identity and ethnic prejudice in children". In D. Gabb, T. Miletic (Eds.). Culture, race and community: Making it work in the new millennium. Melbourne, Victorian Transcultural Psychiatric Unit.

[20] Parisi R., (2017) (eds.), Coreografie familiari fra omosessualità e genitorialità, Aracne editore, Roma

[21] Rinaldi C., (2012), Alterazioni. Introduzione alle sociologie delle omosessualità, Mimesis, Milano 
[22] Roverselli C., (2015), Insegnanti, diversità culturale, questioni di genere. Fatema Mernissi: educare a superare i confini, Anicia, Roma

[23] Ruiz, A.M., Hoster Cabo B., (2013) La competenza letteraria a partire dall'albo illustrato in Campagnaro, M., Dallari M. (eds.), Incanto e racconto nel labirinto delle figure.: Albi illustrati e relazione educativa. Edizioni Erickson, Trento, pp. 139-182

[24] Troyna B., Hatcher R. (1993). Contro il razzismo nella scuola. Il pensiero e le interazioni razziali dei bambini. Trento, Erickson. 